\title{
The Finite Element Modelling of a Rectangular Slab Lying on Multilayer Elastic Soil
}

\author{
Soelarso $^{1}$, Jean-Louis Batoz ${ }^{1 *}$, E Antaluca $^{1}$, F Lamarque $^{1}$ \\ ${ }^{1}$ Laboratoire Avenues Alliance Sorbonne Université-Université de Technologie de Compiègne, France \\ "Corresponding author. Email: jean-louis.batoz@utc.fr
}

\begin{abstract}
The present paper deals with the finite element modeling of a simple raft foundation supported by elastic soil in order to define the best parameters to model more complicated foundation systems in the future taking into accord the soilstructure interaction. The finite element parameters are the type of elements, the contact conditions (sliding or sticking), the size of the domain to consider. In order to validate our models, we compare our results with those of Cuira and Simon, published in 2008 in a Geotechnical Journal. The quantities which are evaluated are the differential settlements, the distribution of reaction stresses and the stresses in both the raft and the supporting multilayer soil.
\end{abstract}

\section{Keywords: FEM, Rectangular Slab, Elastic Soil, Raft Foundation}

\section{INTRODUCTION}

The present paper deals with the linear static analysis of a reinforced concrete raft shallow foundation supported by a multilayer soil using the finite element method. Our objective is to model the structure and supporting soil using 3D classical elements The raft as well as the supporting soil will both be assumed as linear elastic continuum solids within the range of loadings they are subjected to [6]. All computations have been performed using Altair Hyperworks [9], with Hypermesh for the pre-post processing and Optistruct for the solver. We will mostly favor the use of Hexahedron (brick) H8 elements with limited distortion since this type of element in OptiStruct is highly performing (an extension to 3D of the Q4WT element proposed by Wilson and Taylor [7]). That element is able to model the bending of plates with two elements though the thickness without shear locking, however for stress evaluation it is necessary to use more than two elements through the thickness. Regarding the modelling of the soil structure interaction, we will consider two extreme situations, namely sliding contact (zero friction) and sticking contact (or full continuity of displacements). Our results will be compared to those reported by Cuira and Simon [5].

\section{DESCRIPTION OF THE PROBLEM AND RESULTS BY CUIRA AND SIMON}

In [5], the authors are considering the formulas of Steinbrenner/Boussinesq for computing the differential settlements and the slab is modelled by rectangular Kirchhoff plate bending finite elements with three dof per node. Sliding contact is assumed at the interface slabsoil. The authors [2.2] have developed a dedicated software called TASPLAQ taking into account the coupling between the plate finite elements and the Boussinesq formulas. Their approach requires the computations of several matrices such as a flexibility matrix relating the local interaction pressures and the settlements. The final modified stiffness matrix to be "inverted" is not symmetric, but the method avoids discretization of the soil by 3D finite elements.

A rectangular $(\mathrm{RC})$ slab with dimensions $20 \mathrm{~m} \times 20$ $\mathrm{m}$ and thickness $25 \mathrm{~cm}$ is subjected to two concentrated loads of $500 \mathrm{kN}$ at two points. The plate rests on soils with material properties given in figure 1 . The plate is meshed by rectangular 2D plate elements. The results on figure 2 are the distribution of reactions along $\mathrm{AX}$ and the settlements. The maximum values are $45 \mathrm{kPa}$ and 6.6 $\mathrm{mm}$. The authors also report the distribution of bending moments $\mathrm{Mx}$ and $\mathrm{My}$ in $\mathrm{kN} . \mathrm{m} / \mathrm{m}$ along $\mathrm{AX}$ with peak values under the two concentrated loads on the slab (at 8 and $12 \mathrm{~m}$ along $\mathrm{x}$ ), reaching $120 \mathrm{kN} . \mathrm{m} / \mathrm{m}$ (figure 3 ). The authors also reported results using the PLAXIS 3D finite 
element software which is a reference in geotechnical problems [13]. The results are summarized in Table 1.

Table 1. Comparison of TASPLAQ and PLAXIS 3D results [5]

\begin{tabular}{|l|c|c|}
\hline \multicolumn{1}{|c|}{ Maximum values } & TASPLAQ & $\begin{array}{c}\text { PLAXIS } \\
\text { 3D }\end{array}$ \\
\hline Displacement $(\mathrm{mm})$ & 6.6 & 6.6 \\
\hline Reaction of the soil $(\mathrm{kPa})$ & 45 & - \\
\hline Moment $(\mathrm{Mx})(\mathrm{kN} . \mathrm{m} / \mathrm{ml})$ & 108 & 110 \\
\hline Moment $(\mathrm{My})(\mathrm{kN} . \mathrm{m} / \mathrm{ml})$ & 122 & 118 \\
\hline
\end{tabular}

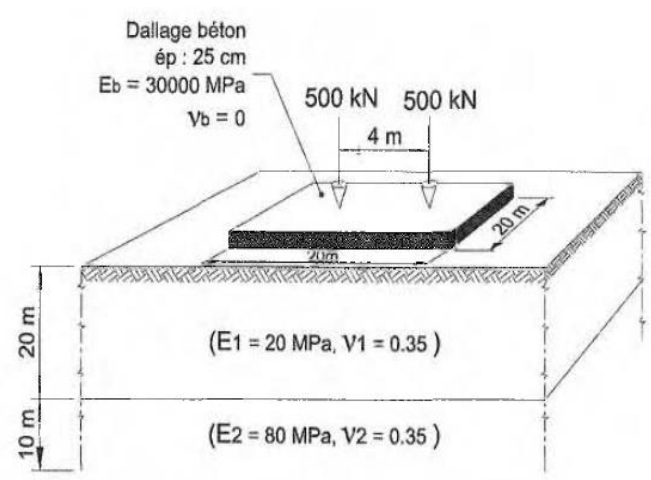

Figure 1 Rectangular slab under concentrated loads and resting on a multilayer soil [5]

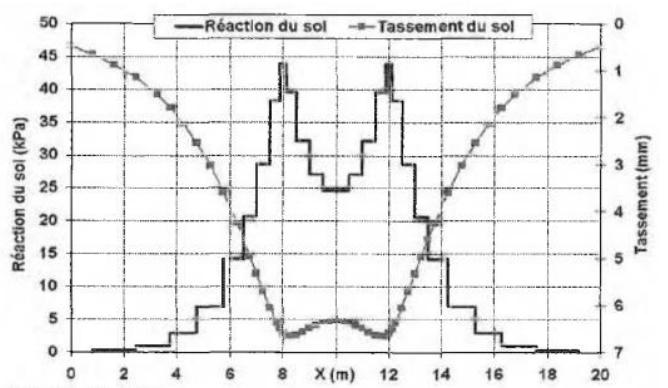

Figure 2 Displacement and reaction of the soil along AX [5]

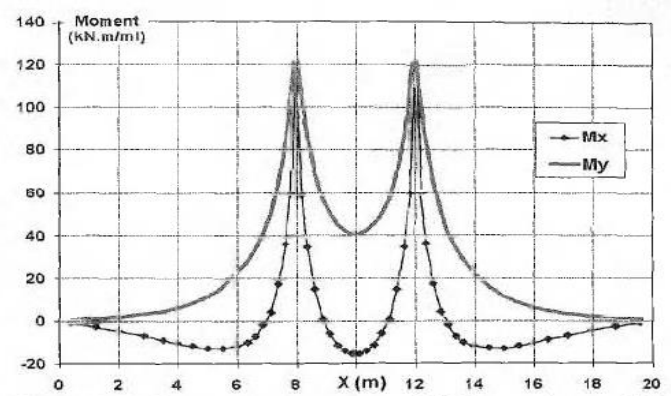

Figure 3 Bending moments of the slab along AX [5]

\section{RESULTS AND DISCUSSION LOADING CONTACT BETWEEN SLAB AND SOIL. INFLUENCE OF THE 3D MESH AND OF DOMAIN SIZE}

We propose to compare the results reported in [5] with results obtained by $3 \mathrm{D}$ FE results using the different software from Hyperworks. We recall that in [5] only the slab is discretized by rectangular bending elements. In our FE model, 3D H8WT element will be used for both the slab and the soil underneath. In this section we will consider, as in [5], sliding contact between the slab and the soil, but two aspects will be discussed: the influence of the 3D meshes and the influence of the size of the domain of soil surrounding the plate, since that aspect was not necessary in [5]. Regarding the size of the domain, we will consider size $20 \times 20,30 \times 30$ and $40 \times 40$ (in m) in $x y$. The lowest surface (level $-30 \mathrm{~m}$ ) is constrained with $\mathrm{w}=0$ and we will also study the influence of free or symmetry conditions on the four vertical surfaces for the domain sizes $20 \times 20$ and $40 \times 40$ (in m) (figure 4). We have been considering three meshes. N0 (18900 H8) corresponds to the mesh of the plate as used by Cuira and Simon [5]. N1 (76 $032 \mathrm{H} 8$ ) and N3 $373248 \mathrm{H} 8$ are finer meshes. For N0 we consider only two elements through the thickness of the slab, but for the other meshes 8 elements through the thickness are considered. Figure 4 shows a 3D view of the N0 mesh for the domain 20x20×30 (in m).

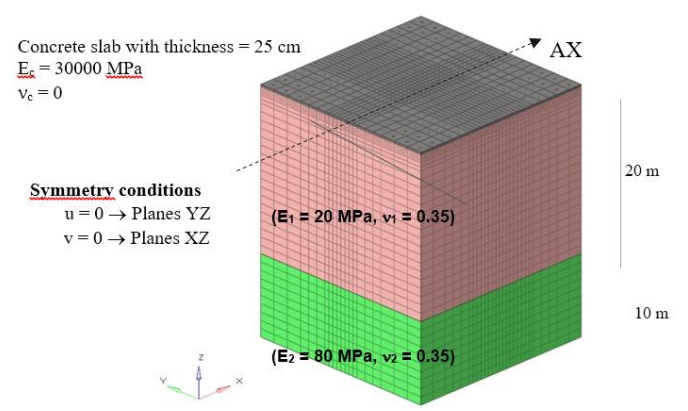

Figure 4 3D model with mesh N0 and domain size 20x20x30 (m)

When the domain size is larger than 20x 20 (in m), there is no contact between the slab and the soil. Results are reported in Tables 2 and 3 for the different meshes and for different constraints on the four vertical surfaces of the 3D domain. We consider both symmetry conditions and stress-free conditions (figure 4). The maximum displacements are increasing when the meshes are refined for both types of constraints (around 12\%) and, as expected, free external surfaces allow more vertical 
displacements (around 17\%). The effect of the increase of the domain size is to reduce the maximum displacements under the loads (by $4 \%$ for symmetry conditions and by $12 \%$ when the surfaces are free).

Table 2 Vertical displacement. Sliding contact. Domain size 20x20x30 m.

\begin{tabular}{|c|c|c|c|}
\hline \multirow{2}{*}{ Mesh } & \multirow{2}{*}{$\begin{array}{c}\text { Number } \\
\text { of Ele- } \\
\text { ments }\end{array}$} & $\begin{array}{c}|c| \\
\text { mymmetry } \\
\text { Conditions }\end{array}$ & Free surfaces \\
\hline N0 & 18900 & 6.77 & 7.99 \\
\hline N1 & 76032 & 6.87 & 8.08 \\
\hline N3 & 373248 & 7.06 & 8.27 \\
& & $\begin{array}{c}7.06 / 6.77= \\
1.12\end{array}$ & $(8.27 / 7.99=1.12)$ \\
& & $(8.27 / 7.06=1.17)$ \\
\hline
\end{tabular}

Table 3 Vertical displacement. Sliding contact. Domain size 40x40x30 m

\begin{tabular}{|c|c|c|c|}
\hline \multirow{2}{*}{ Mesh } & \multirow{2}{*}{$\begin{array}{l}\text { Number } \\
\text { of Ele- } \\
\text { ments }\end{array}$} & \multicolumn{2}{|c|}{ Maximum Displacement (mm) } \\
\hline & & $\begin{array}{l}\text { Symmetry } \\
\text { Conditions }\end{array}$ & Free surfaces \\
\hline NO & 42972 & 6.74 & $\begin{array}{c}6.98 \\
(6.98 / 6.74=1.04)\end{array}$ \\
\hline N1 & 209984 & 6.82 & 7.07 \\
\hline N3 & 630843 & $\begin{array}{c}7.02 \\
(7.02 / 7.06= \\
4 \%)\end{array}$ & $\begin{array}{c}7.26 \\
(7.26 / 8.27=12 \% \\
) \\
(7.26 / 7.02=1.03)\end{array}$ \\
\hline
\end{tabular}

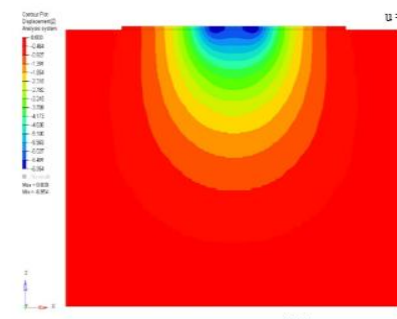

a. Symmetry conditions

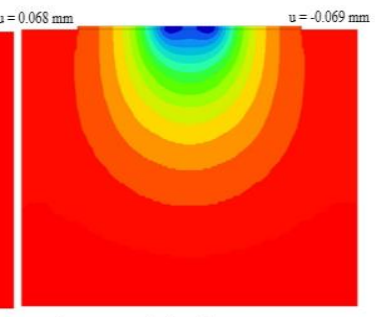

b. Free vertical surfaces
Figure 5 Iso-values of vertical displacement. Sliding contact. N3 mesh with domain size 30x30x30 m.

The isovalues of the $\mathrm{w}$ displacement on a central vertical xz plane are shown on Figure 5 for symmetry conditions (left) and free surfaces (right) for the fine mesh N3 and for the 30x30x30 m domain. More displacements are observed in the case of free surfaces (with $\mathrm{u}=0.069 \mathrm{~mm}$ maximum for the horizontal displacement). The maximum values of the vertical local reactions ( $\square$ zz stresses) are reported for the different domains and two types of conditions on the four vertical planes: for the domain size $20 \times 20 \times 30$ see table 4 , and for $40 \times 40 \times 30$ see table 5 . We can notice a significant influence of the mesh
(29\%), but almost no influence of the domain size and of the stress conditions on the external vertical surfaces. This is due to the local character of the stress concentration on the contact surface. This is confirmed on Figure 6 (isovalues of ozz on the vertical plane Axz).

Table 4 Reaction of the soil ( $\sigma_{\mathrm{zz}}$ stress) sliding contact, domain size 20x20 m

\begin{tabular}{|c|c|c|}
\hline \multirow{2}{*}{ Mesh } & \multicolumn{2}{|c|}{ Maximum Reaction of the soil (kPa) } \\
\cline { 2 - 3 } & Symmetry Condition & Free surfaces \\
\hline N0 & 35.09 & 35.16 \\
\hline N1 & 41.45 & 41.51 \\
\hline N3 & 45.25 & $45.31(45.31 / 35.16=1$. \\
& $(45.25 / 35=1.29)$ & $29)$ \\
\hline
\end{tabular}

Table 5 Reaction of the soil ( $\sigma_{\mathrm{zz}}$ stress) sliding contact domain size 40x40 m

\begin{tabular}{|c|c|c|}
\hline \multirow{2}{*}{ Mesh } & \multicolumn{2}{|c|}{ Maximum Reaction of the soil (kPa) } \\
\cline { 2 - 3 } & Symmetry Condition & Free surfaces \\
\hline N0 & 35.10 & 35.10 \\
\hline N1 & 41.45 & 41.46 \\
\hline N3 & 45.26 & 45.26 \\
\hline
\end{tabular}
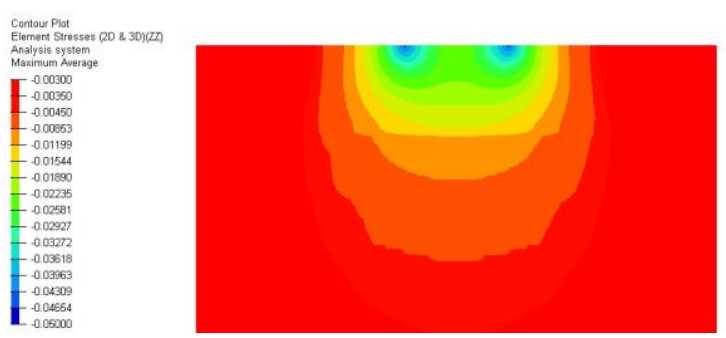

Figure 6 Iso-values of reaction of the soil. Sliding contact. Mesh N3. Domain size 20x20x30 m. (Zoom in Axz plane).

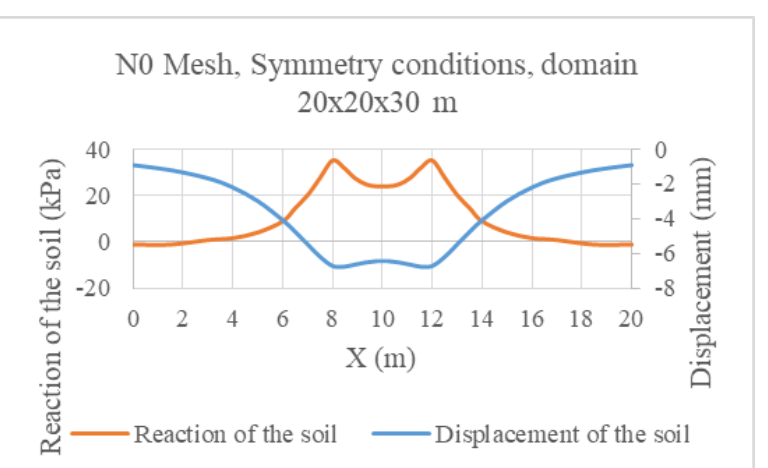

Figure 7 Displacement and reaction of the soil for sliding contact conditions. 
The distribution of the vertical displacement $\mathrm{w}$ and $\sigma_{\mathrm{zz}}$ stress along $\mathrm{AX}$ are given for the domain size of 20x20x30 m, for the fine mesh N0 and for symmetry conditions (figure 7) and for the domain size 40x40x30 m, mesh N3 and free surfaces (figure 8). One can see the local effects of the two concentrated loads in both figures and the influence of the mesh, domain size and stress conditions.

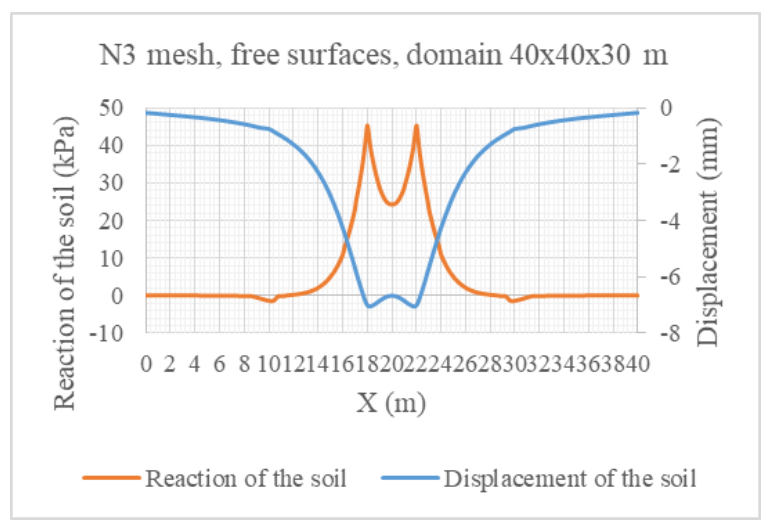

Figure 8 Displacement and reaction of the soil for sliding contact conditions.

As done in [5] we evaluate the bending moments Mx and My on the slab, along AX (figure 4), for the two domain sizes, the two types of boundary conditions on external surfaces and for the different meshes. The bending moments $\mathrm{Mx}$ and My are related to the stresses $\sigma \mathrm{xx}$ and $\sigma y y$. The quality of the results depends on the number of elements through the thickness but also on the number of elements on the surface. This can be seen on tables 6 and 7, when we compare the results using N0 and $\mathrm{N} 3$ for the maximum values of $\mathrm{Mx}$ and My along $\mathrm{AX}$. There is a singularity at the positions of the concentrated loads. However, as for the maximum reaction stresses the domain size is not important, as well as the conditions on the outer vertical surfaces.

Table 6 Bending moments along AX. Sliding contact. Domain size $20 \times 20 \mathrm{~m}$.

\begin{tabular}{|c|c|c|c|c|}
\hline \multirow{2}{*}{ Mesh } & \multicolumn{4}{|c|}{ Maximum Bending Moments $(\mathrm{kN} . \mathrm{m} / \mathrm{m}))$} \\
\cline { 2 - 5 } & \multicolumn{2}{|c|}{ Symmetry Condition } & \multicolumn{2}{c|}{ Free surfaces } \\
\cline { 2 - 5 } & $\mathrm{M}_{\mathrm{x}}$ & $\mathrm{M}_{\mathrm{y}}$ & $\mathrm{M}_{\mathrm{x}}$ & $\mathrm{M}_{\mathrm{y}}$ \\
\hline N0 & 27.28 & 33.43 & 27.34 & 33.51 \\
\hline N1 & 70.36 & 81.31 & 70.45 & 81.44 \\
\hline N3 & $\begin{array}{c}125.32 \\
(125.3 / 27.3 \\
=4.6)\end{array}$ & $\begin{array}{c}123.01 \\
(123 / 33.4 \\
=3.7)\end{array}$ & 125.41 & 123.13 \\
& \multicolumn{3}{|c}{} & \\
\hline
\end{tabular}

Table 7 Bending moments along AX. Sliding contact. Domain size 40x40 m.

\begin{tabular}{|c|c|c|c|c|}
\hline \multirow{2}{*}{ Mesh } & \multicolumn{3}{|c|}{ Maximum Bending Moments $(\mathrm{kN} . \mathrm{m} / \mathrm{m})$} \\
\cline { 2 - 5 } & Symmetry Condition & \multicolumn{2}{c|}{ Free surfaces } \\
\cline { 2 - 5 } & $\mathrm{Mx}$ & $\mathrm{My}$ & $\mathrm{Mx}$ & $\mathrm{My}$ \\
\hline $\mathrm{N} 0$ & 27.43 & 33.54 & 27.43 & 33.54 \\
\hline $\mathrm{N} 1$ & 70.60 & 81.49 & 70.60 & 81.48 \\
\hline N3 & 125.56 & 123.18 & 125.56 & 123.18 \\
\hline
\end{tabular}
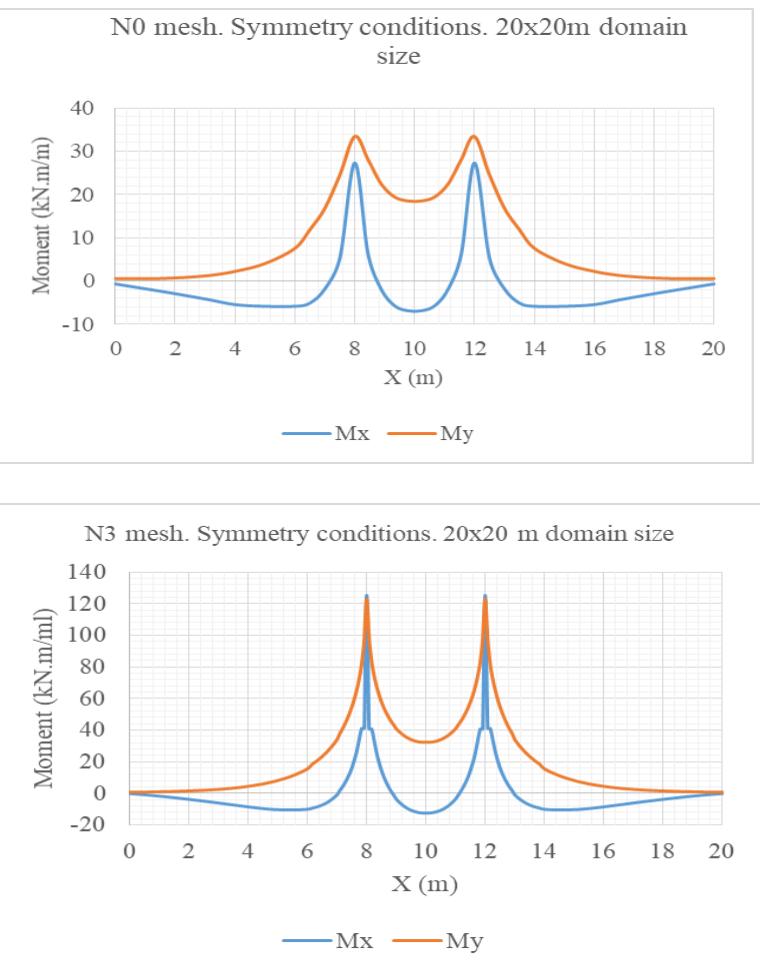

Figure 9 Bending moments $\mathrm{Mx}$ and $\mathrm{My}$ along $\mathrm{AX}$. Sliding contact. Mesh N0 and N3.

The distribution of Mx and My along AX considering the domain size $20 \times 20 \mathrm{~m}$, the symmetry conditions on the external vertical planes and for mesh N0 and N3 are given on Figure 9. One can clearly see the strong variations of $\mathrm{Mx}$ and $\mathrm{My}$ along $\mathrm{x}$, with the peak values very sensitive to the mesh. It is also observed that $\mathrm{Mx}$ is changing of sign along $\mathrm{x}$, whereas My remains positive.

\section{RESULTS CONSIDERING STICKING CONTACT}

In this section we present the results considering sticking contact between the plate and the supporting soil. This is equivalent to assuming a full continuity of the displacements at the soil structure interface. Results 
for the maximum displacements are reported in tables 8 and 9. The influence of the mesh is now limited to 5\%, it was $12 \%$ for sliding (section 2), the influence of the boundary conditions is more important (20\% to $5 \%$ in the sliding case). In the average, case per case, the difference between sticking and sliding contact is a reduction of the maximum displacement between 5 to $3 \%$.

Table 8. Vertical displacement (sticking contact) with domain $20 \mathrm{~m}$ x $20 \mathrm{~m}$.

\begin{tabular}{|c|c|c|c|}
\hline \multirow{2}{*}{ Mesh } & \multirow{2}{*}{$\begin{array}{c}\text { Number } \\
\text { of Ele- } \\
\text { ments }\end{array}$} & $\begin{array}{c}\text { Maximum Displacement }(\mathrm{mm}) \\
\text { Conditions }\end{array}$ & Free surfaces \\
\hline N0 & 18900 & 6.50 & $\begin{array}{c}7.78 \\
(7.78 / 6.50=1.2)\end{array}$ \\
\hline N1 & 76032 & 6.61 & 7.87 \\
\hline N3 & 373 & 6.80 & $\begin{array}{c}8.06 \\
\end{array}$ \\
& 248 & $(6.8 / 6.5=1.05)$ & $(8.06 / 7.78=1.04)$ \\
& & & $(8.06 / 6.80=1.185)$ \\
\hline
\end{tabular}

Table 9. Vertical displacement (sticking contact) with domain $40 \mathrm{~m} \mathrm{x} 40 \mathrm{~m}$.

\begin{tabular}{|c|c|c|c|}
\hline \multirow{2}{*}{ Mesh } & \multirow{2}{*}{$\begin{array}{c}\text { Number } \\
\text { of Ele- } \\
\text { ments }\end{array}$} & $\begin{array}{c}\text { Maximum Displacement }(\mathrm{mm}) \\
\text { Conditions }\end{array}$ & Free surfaces \\
\hline N0 & 42972 & 6.41 & 6.69 \\
& & & $(6.69 / 6.41=1.05)$ \\
\hline N1 & 209984 & 6.51 & 7.79 \\
\hline N3 & 630843 & 6.70 & 6.98 \\
& & $(6.7 / 6.41=1$. & $(6.98 / 6.69=1.04)$ \\
& & $045)$ & $(6.98 / 6.70=1.04)$ \\
\hline
\end{tabular}

The isovalues of the displacements in the verti-cal plane Axz are shown in figure 10, for a domain size of $30 \times 30 \times 30 m$ and for the two types of boundary con-ditions on the vertical planes. It is clear that the free conditions allow more vertical displacements on the top surface, up to the vertical planes, (with $\mathrm{u}=0.073 \mathrm{~mm}$ maximum compared to $\mathrm{u}=0.68 \mathrm{~mm}$ on Figure 5).

As for the sliding contact, the reactions of the soil are not influenced by the domain size (Tables 10 and 11) and by the boundary conditions on the external vertical surfaces. It is also important to see that the values of reactions are very comparable between sliding and sticking contact (only 1 to $3 \%$ difference). The peak values of reactions are influenced by the number of elements with a significant gap between the N0 mesh and the N1 mesh (Figures 12 and 13).

We also find that the distribution of bending moments is not influenced by the contact conditions between the slab and the soil (Tables 12 and 13). The results presented in the previous section (figure 9) are not significantly changing as seen on Figure14.
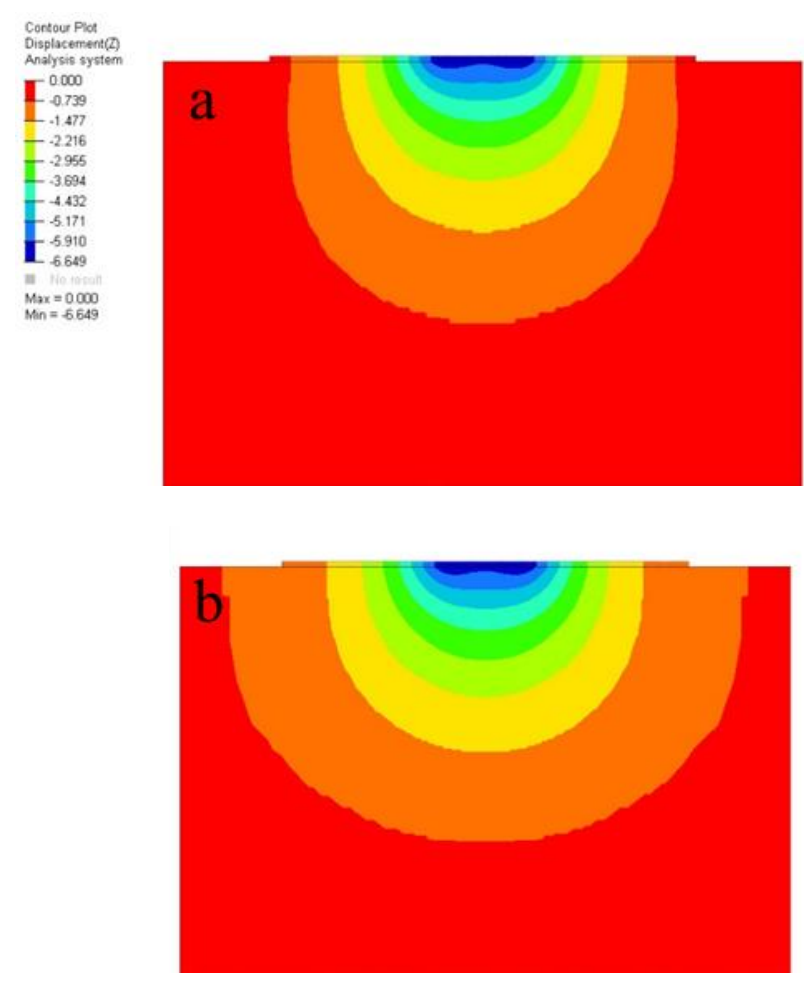

Figure 10. Iso-values of vertical displacement. Sticking contact. N3 mesh. Domain size 30x30x30 m (zoom); (a) Symmetry conditions; (b) free surfaces.

Table 10. Reaction of the soil ( $\sigma_{\mathrm{zz}}$ stress). Sticking contact. Domain size 20x20x30 m.

\begin{tabular}{|c|c|c|}
\hline \multirow{2}{*}{ Mesh } & \multicolumn{2}{|c|}{ Reaction of the soil $(\mathrm{kPa})$} \\
\cline { 2 - 3 } & Symmetry Condition & Free surfaces \\
\hline N0 & 34.72 & 34.81 \\
\hline N1 & 42.38 & 42.45 \\
\hline N3 & 46.74 & 46.81 \\
\hline
\end{tabular}

Table 11. Reaction of the soil ( $\sigma_{\mathrm{zz}}$ stress). Sticking contact. Domain size 40x40x30 m.

\begin{tabular}{|c|c|c|}
\hline \multirow{2}{*}{ Mesh } & \multicolumn{2}{|c|}{ Reaction of the soil (kPa) } \\
\cline { 2 - 3 } & Symmetry Conditions & Free surfaces \\
\hline N0 & 34.72 & 34.73 \\
\hline N1 & 42.38 & 42.39 \\
\hline N3 & 46.75 & 46.75 \\
\hline
\end{tabular}




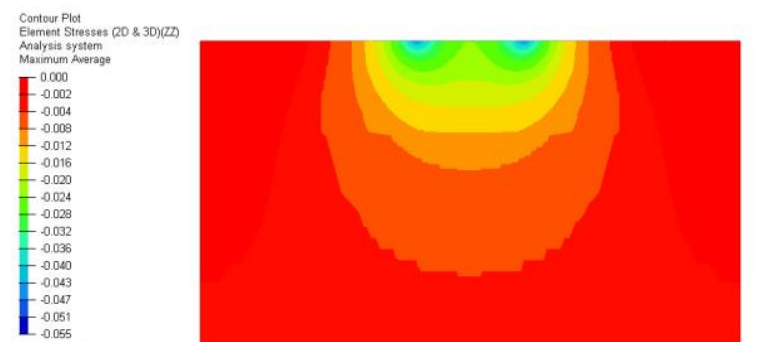

Figure 11. Iso-values of reaction of the soil. Sticking contact. Mesh N0. Domain size 20x20x30 m. (Zoom in A xz plane).

Figure 11 shows the isovalues of the reactions of the soil in the vertical Axz plane (zoom). It is quite similar to figure 6 (sliding contact).

\section{N0 (sticking contact/Symmetry/(20x20m)}

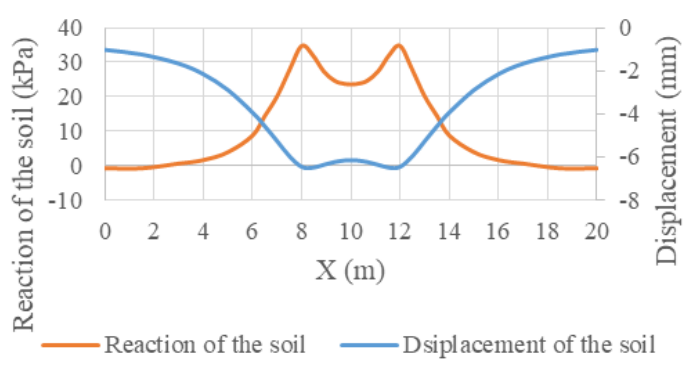

Figure 12. Displacement and reaction of the soil

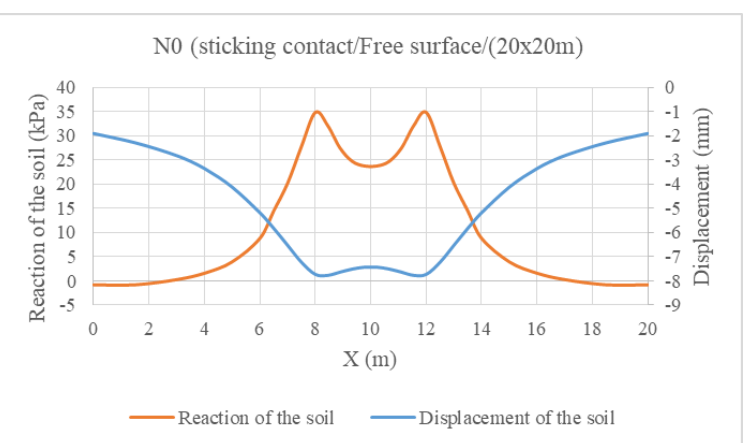

Figure 13. Displacement and reaction of the soil

Table 12. Bending Moment of the slab (sticking contact) with domain $20 \times 20 \mathrm{~m}$

\begin{tabular}{|c|c|c|c|c|}
\hline \multirow{2}{*}{ Mesh } & \multicolumn{3}{|c|}{ Bending Moment $(\mathrm{kN} . \mathrm{m} / \mathrm{ml})$} \\
\cline { 2 - 5 } & Symmetry Condition & \multicolumn{2}{c|}{ Free surfaces } \\
\cline { 2 - 5 } & $\mathrm{Mx}$ & $\mathrm{My}$ & $\mathrm{Mx}$ & $\mathrm{My}$ \\
\hline N0 & 27.38 & 33.21 & 27.16 & 33.15 \\
\hline N1 & 70.07 & 80.47 & 69.88 & 80.45 \\
\hline N3 & 125.00 & 122.14 & 124.81 & 122.11 \\
\hline
\end{tabular}

Table 13. Bending Moment of the slab (sticking contact) with domain $40 \times 40 \mathrm{~m}$

\begin{tabular}{|c|c|c|c|c|}
\hline \multirow{2}{*}{ Mesh } & \multicolumn{4}{|c|}{ Bending Moment (kN.m/ml) } \\
\cline { 2 - 5 } & Symmetry Condition & Free surfaces \\
\cline { 2 - 5 } & $\mathrm{Mx}$ & My & Mx & My \\
\hline N0 & 27.38 & 33.29 & 27.34 & 33.25 \\
\hline N1 & 70.15 & 80.61 & 70.11 & 80.57 \\
\hline N3 & 125.08 & 122.27 & 125.04 & 122.23 \\
\hline
\end{tabular}

\section{N0 (Sticking/Symmetry/(20x20m)}

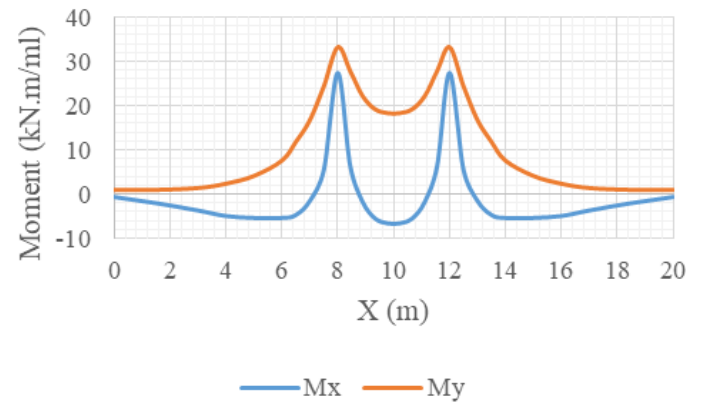

Figure 14. Bending moments (Sticking contact) (N0)

Addition of CNC to PLA matrix was increase tensile strength and elongation at break from edible film. Mechanical properties of edible films that ap-proached the standard edible film were obtained by adding $20 \%$ CNC to the PLA matrix (T5 100: 20), with tensile strength and elongation at break were $7.68 \mathrm{MPa}$ and $22.4 \%$ respectively. Based on the results of func-tional group analysis, it appears that the PLA/CNC edi-ble film composite has been formed.

In this study we have proposed different 3D Finite Element models for the analysis of the problem proposed by Cuira and Simon [5], using the FE software Altair Hyperworks. Different aspects have been consid-ered: influence of the domain sizes, influence of the boundary conditions on the external vertical planes, influence of the mesh density in the slab and in the soil. We also compare the results considering sliding contact and sticking contact at the slab soil interface. The re-sults are summarized in tables 14 to 16 for the maxi-mum displacements, maximum reactions and maxi-mum bending moments. Our FE results are compared with some values reported in [5] (software TASPLAQ and PLAXIS 3D). 
Table 14. Comparison of the maximum displacements

\begin{tabular}{|c|c|c|c|c|c|c|}
\hline \multirow{3}{*}{ Domain of soil } & \multicolumn{6}{|c|}{ Maximum Displacement (mm) } \\
\hline & \multicolumn{2}{|c|}{ Sliding Contact } & \multicolumn{2}{|c|}{ Sticking contact } & \multirow[t]{2}{*}{ TASPLAQ } & \multirow[t]{2}{*}{ PLAXIS 3D } \\
\hline & $\begin{array}{l}\text { Symmetry } \\
\text { Conditions }\end{array}$ & Free surfaces & $\begin{array}{l}\text { Symmetry } \\
\text { Conditions }\end{array}$ & Free surfaces & & \\
\hline \multicolumn{7}{|l|}{$20 \times 20 \mathrm{~m}$} \\
\hline No & 6.77 & 7.99 & 6.50 & 7.78 & \multirow[t]{7}{*}{6.6} & \multirow[t]{7}{*}{6.6} \\
\hline N1 & 6.87 & 8.08 & 6.61 & 7.87 & & \\
\hline N3 & 7.06 & 8.27 & 6.80 & 8.06 & & \\
\hline \multicolumn{5}{|l|}{$40 \times 40 \mathrm{~m}$} & & \\
\hline No & 6.74 & 6.98 & 6.41 & 6.69 & & \\
\hline N1 & 6.82 & 7.07 & 6.51 & 7.79 & & \\
\hline N3 & 7.02 & 7.26 & 6.70 & 6.98 & & \\
\hline
\end{tabular}

Table 15. Comparison of the maximum reactions of the soil.

\begin{tabular}{|c|c|c|c|c|c|c|}
\hline \multirow{3}{*}{ Domain of soil } & \multicolumn{6}{|c|}{ Maximum Displacement (mm) } \\
\hline & \multicolumn{2}{|c|}{ Sliding Contact } & \multicolumn{2}{|c|}{ Sticking contact } & \multirow[t]{2}{*}{ TASPLAQ } & \multirow[t]{2}{*}{ PLAXIS 3D } \\
\hline & $\begin{array}{l}\text { Symmetry } \\
\text { Conditions }\end{array}$ & Free surfaces & $\begin{array}{l}\text { Symmetry } \\
\text { Conditions }\end{array}$ & Free surfaces & & \\
\hline \multicolumn{7}{|l|}{$20 \times 20 \mathrm{~m}$} \\
\hline No & 35.09 & 35.16 & 34.72 & 34.81 & \multirow[t]{7}{*}{45} & \multirow[t]{7}{*}{45} \\
\hline N1 & 41.45 & 41.51 & 42.38 & 42.45 & & \\
\hline N3 & 45.25 & 45.31 & 46.74 & 46.81 & & \\
\hline \multicolumn{5}{|l|}{$40 \times 40 \mathrm{~m}$} & & \\
\hline No & 35.10 & 35.10 & 34.72 & 34.73 & & \\
\hline N1 & 41.45 & 41.46 & 42.38 & 42.39 & & \\
\hline N3 & 45.26 & 45.26 & 46.75 & 46.75 & & \\
\hline
\end{tabular}

Table 16 Comparison of bending moments.

\begin{tabular}{|c|c|c|c|c|c|c|c|c|c|c|c|c|}
\hline \multirow{4}{*}{$\begin{array}{l}\text { Domain } \\
\text { of soil }\end{array}$} & \multicolumn{12}{|c|}{ Bending Moments (kN.m/m) } \\
\hline & \multicolumn{4}{|c|}{ Sliding Contact } & \multicolumn{4}{|c|}{ Sticking contact } & \multirow{2}{*}{\multicolumn{2}{|c|}{ TASPLAQ }} & \multirow{2}{*}{\multicolumn{2}{|c|}{ PLAXIS 3D }} \\
\hline & \multicolumn{2}{|c|}{$\begin{array}{l}\text { Symmetry } \\
\text { Conditions }\end{array}$} & \multicolumn{2}{|c|}{ Free surfaces } & \multicolumn{2}{|c|}{$\begin{array}{l}\text { Symmetry } \\
\text { Conditions }\end{array}$} & \multicolumn{2}{|c|}{ Free surfaces } & & & & \\
\hline & $\mathrm{Mx}$ & My & $\mathrm{Mx}$ & My & $\mathrm{Mx}$ & My & $\mathrm{Mx}$ & My & $\mathrm{Mx}$ & My & $\mathrm{Mx}$ & My \\
\hline No & 27.28 & 33.43 & 27.34 & 33.51 & 27.38 & 33.21 & 27.16 & 33.15 & & & & \\
\hline N1 & 70.36 & 81.31 & 70.45 & 81.44 & 70.07 & 80.47 & 69.88 & 80.45 & & & & \\
\hline N3 & 125.32 & 123.01 & 125.41 & 123.13 & 125.00 & 122.14 & 124.81 & 122.11 & 108 & 122 & 110 & 118 \\
\hline \multicolumn{13}{|l|}{$40 \times 40 \mathrm{~m}$} \\
\hline No & 27.43 & 33.54 & 27.43 & 33.54 & 27.38 & 33.29 & 27.34 & 33.25 & & & & \\
\hline N1 & 70.60 & 81.49 & 70.60 & 81.48 & 70.15 & 80.61 & 70.11 & 80.57 & & & & \\
\hline N3 & 125.56 & 123.18 & 125.56 & 123.18 & 125.08 & 122.27 & 125.04 & 122.23 & & & & \\
\hline
\end{tabular}


3D FEM based on linear elasticity can be efficiently used to solve geotechnical problems of shallow foundation systems supported by elastic soils when the maximum soil compression stress is much smaller $(<1 / 3)$ compared to the soil ultimate bearing stress capacity (also taking into account safety factors). Our results are in good agreement regarding settlements and structure internal stresses obtained by other numerical models presented in [5]. We believe that we can now consider the static analysis of SNSF structures in the context of real constructions involving an upper structure supported by a shallow foundation (raft or SNSF type), as shown in [10 to 12$]$.

\section{CONCLUDING REMARKS}

The main conclusions are the FE Models we built are able to solve the problem with efficiency, precision and versatility to model the soil-structure interaction. In the present situation the sliding contact and the sticking contact are giving almost the same results for the reactions and for the bending moments but slightly more displacements when considering sliding contact ( +5 to $3 \%$ ). Therefore, sticking contact, or full continuity of displacement, is a satisfactory and simpler approach for simulation in geotechnical problem of soil structure interaction. Our FEM results are in good agreement with the results reported in [5] for the maximum displacements, reactions and bending moments.

\section{REFERENCES}

[1] Batoz J.L, Dhatt G. (1990). Modélisation des structures par éléments finis "solides élastiques", Vol. 1, Hermés Science Publications, France.

[2] Dhatt G., Touzot G., The finite element displayed, J. Wiley, 1984.

[3] Bathe K.J., Finite element procedures, Prentice Hall, 1996.

[4] Zienkiewicz, O.C., Taylor, R.L., Zhu, J.Z., The Finite element method. Its basis and fundamentals, Elsevier, $6^{\text {th }}$ Edition, 2005.

[5] Cuira F, Simon B. (2008). "Modélisation 3D simplifiée d'une plaque sur sol multicouche élastique", Revenue Francaise Geotechnique, No 124, pp 3-17, 2008.

[6] Terzaghi K. "Theoretical soil mechanics -Theory of Semi-infinite elastic solids, 1943.

[7] Wilson, E.L., Taylor, R., Doherty, S.P., Ghaboussi, J, (1973), "Incompatible displacement models", in Fenves et al. (eds), Numerical and Computer Methods in Structural Mechanics, Academic Press, New York, pp.43-57,1973.

[8] Darjanto H, Irsyam M, Retno S.R, (2015), "Full Scale Load Test on The Spider Net System", 77:11(2015)
73-82. Jurnal Teknologi (Sciences \& Engineering) Universiti Teknologi Malaysia.

[9] https://www.altair.com/hyperworks/

[10] Soelarso , Antaluca E. , Batoz J.L. , Lamarque F., On the finite element bearing capacity analysis of a rib system to be used as shallow foundation construction, IOP Conf. Ser.: Mater. Sci. Eng. 673 012030, 2019

[11] Soelarso , Antaluca E. , Batoz J.L. , Lamarque F., On the FE modeling of a SNSF shallow foundation system in the context of soft soil in Indonesia, ACEM20 Structures20 Conference, CS220 Session Seoul, 25-28 August 2020.

[12] Soelarso , Antaluca E. , Batoz J.L. , Lamarque F., On the finite element modeling of a particular shallow foundation system for soft soil Coupled Systems Mechanics, Vol. 10, No. 3 (2021) 247-261.

[13] https://www.plaxis.com/ 